\title{
Microhabitat segregation in three rocky intertidal fish species in Portugal: does it reflect interspecific competition?
}

\author{
C. FARIA* AND V. Almada \\ Unidade de Investigação, em Eco-Etologia, Instituto Superior de Psicologia Aplicada, \\ R. Jardim do Tabaco 34, P-1149-041 Lisboa, Portugal
}

(Received 18 April 2000, Accepted 11 August 2000)

\begin{abstract}
Recruits of Lipophrys pholis, Coryphoblennius galerita and Gobius cobitis spend the low tide under water in pools, and in the case of G. cobitis also in channels. The pools used by the two blenniids show greater similarity than those used by G. cobitis. Larger juveniles and adults of C. galerita continue to use the same type of pools, which are temporarily abandoned by the males during the breeding season when they use emersed holes and crevices as nests. The much faster growing $L$. pholis and $G$. cobitis leave the pools in their first autumn, when they are c. $7 \mathrm{~cm}$ long. Whereas G. cobitis $>7 \mathrm{~cm}$ move to channels and large upper pools, with a smooth substratum, sand and boulders, L. pholis begin to use emersed crevices where they spend low tide often in large groups. When L. pholis or C. galerita were added or removed selectively from pools, their numbers returned to pre-experimental levels after 2 weeks, suggesting that, although intraspecific competition may be strong, interspecific competition was unlikely to explain these results fully.

(C) 2001 The Fisheries Society of the British Isles
\end{abstract}

Key words: Blenniidae; Gobiidae; intertidal fishes; microhabitat segregation; ontogenetic niche shifts; interspecific competition.

\section{INTRODUCTION}

The structure of rocky intertidal fish communities, and more generally, those of reef fishes, has attracted much attention (Smith \& Tyler, 1973; Luckhurst \& Luckhurst, 1978; Robertson \& Lassig, 1980; Alevizon et al., 1985; Clarke, 1989; Greenfield \& Johnson, 1990; Connel \& Jones, 1991; Pitts, 1991; Syms, 1995).

The attempts to investigate the principles governing the organization of rocky intertidal fish communities have taken a number of major directions. Many studies have focused on specific dimensions along which different members of the communities may differ, including vertical distribution (Gibson, 1972; Burgess, 1978; Yoshiyama, 1981; Costello, 1992), shelter availability and habitat complexity (Behrents, 1987; Koppell, 1988; Kotrschal, 1988; Wilkins \& Myers, 1993) or differentiation of trophic niches (Gibson, 1960; MacPherson, 1981; Yoshiyama, 1980; Zander, 1982). Other studies have focused on the possible role of competition as a mechanism structuring these communities (Larson, 1980a,b,c; Mayr \& Berger, 1992), while still others have centred on long-term patterns of persistence and resilience of these rock intertidal fish assemblages (Thomson \& Lehner, 1976; Grossman, 1982, 1986; Yoshiyama et al., 1986; Faria \& Almada, 1999). However, there is no firm evidence on the relative importance of the different mechanisms likely to shape rocky intertidal fish

*Author to whom correspondence should be addressed. Tel.: +35121 8811700; email: cfaria@ispa.pt 145 
communities and in a recent review Gibson \& Yoshiyama (1999) state that: 'the interplay among microhabitat choice, food specialization, potential competition between species, and predation pressure undoubtedly has influenced the evolution and population abundance of intertidal fishes. However, the mechanisms involved and their selective importance are only beginning to be discerned.'

Despite the appreciable number of studies on the ecology of intertidal fishes on European shores (Gibson, 1967; Costello, 1992; MacPherson, 1994), the classical study of Gibson (1972) on the west coast of France is still one of the most comprehensive and more insightful studies in the north-eastern Atlantic Ocean.

In the present paper, the distributional ecology of intertidal fishes is examined at another locality in the north-eastern Atlantic. Specifically, data are provided from a long term survey programme, and on the patterns of microhabitat use of some of the commonest resident fishes in Portugal, with special emphasis on the ecological differences among distinct life history stages of each species. Preliminary experimental data are presented, aimed to assess the relative importance of interspecific competition among the species involved.

\section{MATERIALS AND METHODS}

The study period ranged from January 1993 to December 1999. Three monitoring sites were established, on the Portuguese west coast, at Amoreira (site 1$)\left(37^{\circ} 18^{\prime} \mathrm{N} ; 9^{\circ} 8^{\prime} \mathrm{E}\right)$, Avencas and S. Pedro do Estoril (site 2) $\left(38^{\circ} 41^{\prime} \mathrm{N} ; 9^{\circ} 22^{\prime} \mathrm{W}\right)$ and Gelfa (site 3) $\left(41^{\circ} 47^{\prime} \mathrm{N}\right.$; $\left.9^{\circ} 8^{\prime} \mathrm{E}\right)$.

Site 2 was visited monthly through most of the study period, except during 1996 and 1999 when it was visited at intervals of 2 months. Sites 1 and 3 were only surveyed between 1996 and 1999. Site 1 was visited monthly from June 1997 to June 1998 and site 3 from June 1998 to June 1999, and they were visited at 2 month intervals during the remainder of the survey period.

A total of 54 tide pools was monitored along transects perpendicular to the shore (15 at site 1, 12 at site 2 and 27 at site 3 ). For each pool, the following data were collected: surface area and depth of the pool, amount of algal cover, type of substratum (1 for sand, 2 for mixed substratum and 3 for rock), complexity of the pool, the time at which the incoming water entered the pool on the flooding tide, and the amount of sea urchins and barnacles present in and around the pool. The surface area was measured using a square grid, with square cells of $10 \times 10 \mathrm{~cm}$, which was laid over the pool. The area was estimated as the number of grid cells that lay over the water surface. The same grid was used to estimate the amount of algal cover, scoring the number of cells that overlaid areas with visible algal growth (Raffaeli \& Hawkins, 1996). Complexity was estimated with a subjective five-points index: 1 corresponding to pools with smooth rock surfaces and 5 to those whose surface was entirely covered with sea urchin depressions and irregular masses of calcareous algae.

During each inspection, all the fishes that could be located in the pool were collected with a hand-net. Species, sex (when possible) and total length $\left(L_{\mathrm{T}}\right)$ were recorded. All the fishes were kept in a bucket with sea water until collecting was completed and were returned subsequently to the same pool. Each census consisted of several visits to the pool, separated by periods of several minutes, during which other pools were visited. A census was considered complete after a visit in which no fishes were seen, despite intensive probing in holes and crevices. No anaesthetic was used because previous work showed no significant differences in the distributions of fish sizes and abundances between samples collected with and without anaesthetic (Faria \& Almada, 1999).

At each site, a number of small holes and crevices on the emersed rocks were also monitored regularly, with the help of a portable light. At each inspection, the presence of 
fish, its length visually estimated as $<7$ or $>7 \mathrm{~cm}$, species identity and the presence of eggs were recorded. For each shelter, the width and height of the aperture and the shape of the shelter (tube or chamber) was recorded.

From June 1993 to May 1994, a set of 10 small channels at site 2, directly connected to the sea and penetrating the rock platform in an oblique direction relative to the shore, were inspected monthly. Each inspection consisted of a visual census in which every fish observed during a 5 -min interval, in every $2 \mathrm{~m}$ of channel, was recorded. This procedure was repeated until the entire channel was censused. For each observed fish, species and length, visually estimated as $<7$ and $>7 \mathrm{~cm}$, were recorded. The length of every channel was measured and each channel was divided into two zones: one corresponding to the mouth of the channel, where the effect of wave action was still noticeable; and a terminal section, further from the sea, without observable turbulence. For each of the two zones the following data were recorded: maximum and minimum width and depth, type of substratum and the amount of algal cover. The last two measures were defined as for tide pools.

In this study special attention was given to the commonest resident fish species, Lipophrys pholis (Linnaeus, 1758), Coryphoblennius galerita (Linnaeus, 1758) and Gobius cobitis (Pallas, 1811), and the quantitative analysis was confined to these species. Recruits were considered to be all fish $<3 \mathrm{~cm} L_{\mathrm{T}}$ (Faria \& Almada, 1999). For L. pholis and $G$. cobitis, fish from 3-6 $\mathrm{cm} L_{\mathrm{T}}$ were considered as juveniles and fish $>6 \mathrm{~cm} L_{\mathrm{T}}$ as adults. For C. galerita, fish $\leqslant 3 \mathrm{~cm} L_{\mathrm{T}}$ were considered as juveniles and fish $>3 \mathrm{~cm} L_{\mathrm{T}}$ as adults.

Removal and addition experiments were made at site 2, using $L$. pholis and C. galerita. The experiments were made in three additional sets of pools that were not included in the group of pools regularly surveyed: 10 control pools, 10 removal pools (from which fishes were removed) and 10 additional pools (to which fishes were added). In control pools, all the fishes that could be collected were marked by cutting specific rays of the dorsal and anal fins before release. In removal pools, the fishes of one of the two species were marked also but were released in tide pools $>500 \mathrm{~m}$ away. The other species present in the pool were only measured and were returned to the same pool. The additional pools, that received the fishes removed from the removal pools, had been censused previously in the same low tide. All three sets of pools were re-censused 15 and 30 days after the manipulation. This procedure was performed in May/June and November/December 1998 for L. pholis and 1999 for C. galerita. For all experimental and control pools, the number of fishes for each species prior to the manipulation and the number found 2 weeks and 30 days after were compared. The net gain or loss of fishes for that period was computed for each pool and patterns of change in the number of fish of control, addition and removal pools was compared using a Kruskall-Wallis analysis of variance.

Data analysis was performed using the computer programmes Statistica for Windows (version 4.5) (Statsoft Inc.). The analysis of contingency tables was performed using ACTUS. This simulation procedure, developed for the analysis of contingency tables, is presented in Estabrook \& Estabrook (1989). It has two important advantages over the traditional $\chi^{2}$ test of independence. First, it is free from the assumptions under which the $\chi^{2}$ distribution can be used, for instance concerning the lower limits of the expected values in the table. Second, apart from assessing the overall significance of the table, the test allows assessment of the significance of deviations between observed and expected frequencies for each individual cell.

\section{RESULTS}

\section{FISH DISTRIBUTION AMONG POOLS, CHANNELS AND CREVICES}

Inspection of the distribution of recruits, juveniles and adults of the three species in pools, channels and crevices (Table I) $\left(\chi^{2}=6396 \cdot 87\right.$, d.f. $\left.=10, P<0 \cdot 001\right)$, shows that for L. pholis, recruits and juveniles were significantly more abundant in pools than expected by chance $(P<0.001)$, while the adults were significantly more abundant than expected by chance in crevices $(P<0.001)$. Indeed, $87 \%$ of 





TABLE II. Total number of fishes of the species studied observed in the channels from June 1993 to May 1994

\begin{tabular}{lccc}
\hline & L. pholis & C. galerita & G. cobitis \\
\hline $\begin{array}{l}\text { First (mouth) section of the channel } \\
\text { Terminal section of the channel }\end{array}$ & 120 & 42 & 236 \\
\hline
\end{tabular}

all adults of this species were found in crevices. In contrast, all ontogenetic stages of $C$. galerita were significantly more abundant in pools $(P<0 \cdot 001)$, with $92 \%$ of the individuals found there. For the gobies, all developmental stages that can be detected by visual census were significantly more common in channels $(P<0.001)$, although a substantial proportion of juveniles and immatures were found in pools $(52 \%)$. All life stages of the gobies were absent from emersed crevices and holes.

The distribution of the fishes within the channels also differed among the species (Table II) $\left(\chi^{2}=33 \cdot 66\right.$, d.f. $\left.=2, P<0 \cdot 001\right)$. Both blennies, when present in channels, were significantly more abundant than expected by chance in the first (mouth) section of the channels $(P<0 \cdot 05)$, near the connection with the sea where algal cover was more abundant and rocky substrata more complex. In contrast, G. cobitis occupied preferentially the terminal sections $(P<0 \cdot 01)$, which were sheltered from wave action and had smooth substrata, abundant sand and boulders, and much less abundant algal growth (with dense Enteromorpha sp. in sections furthest from the sea).

Both L. pholis and C. galerita were found in emersed holes and crevices. However, the dimensions and shapes of the shelters used by the two species were significantly different. L. pholis, which attains a much larger size, tended to use shelters with larger apertures (aperture height: mean $=2.89 \mathrm{~cm}$, S.D. $=1.29$, range $=1 \cdot 0-9.0 \mathrm{~cm}$; aperture width: mean $=11.13 \mathrm{~cm}$, S.D. $=17 \cdot 89$, range $=2.0$ $100 \cdot 0 \mathrm{~cm}, n=70$ ) that formed chambers inside rocks and where many fishes often occurred together. In contrast, the holes used by $C$. galerita tended to have small apertures (aperture height: mean $=1.78 \mathrm{~cm}$, S.D. $=0.54$, range $=1.0-2.5 \mathrm{~cm}$; aperture width: mean $=2.37 \mathrm{~cm}$, S.D. $=0.82$, range $=1 \cdot 5-5.0 \mathrm{~cm}, n=30$ ) with dimensions fitting more or less tightly the body of the fish. The differences in aperture dimensions of holes used by $L$. pholis and $C$. galerita were statistically significant (Mann-Whitney $U$-test: aperture height $Z=-5.042, P<0.001, N_{L \text {. pholis }}=70$, $N_{C \text {. galerita }}=30$ and aperture width $Z=-7 \cdot 172, \quad P<0.001, \quad N_{L \text {. pholis }}=70$, $\left.N_{C \text {. galerita }}=30\right)\left(\chi^{2}=35 \cdot 287\right.$, d.f. $\left.=1, P<0 \cdot 001\right)$. L. pholis occupied preferentially chambers or crevices $(P<0 \cdot 01)$ and $C$. galerita tubular holes $(P<0 \cdot 001)$.

\section{TEMPORAL AND ONTOGENETIC PATTERNS OF OCCURRENCE OF THE FISHES IN POOLS}

G. cobitis was present in pools only from settlement up to a size of 7-8 $\mathrm{cm} L_{\mathrm{T}}$. They recruit to the pools from April to September or October (Table III), which is in agreement with the breeding season of the species in Portugal lasting from 


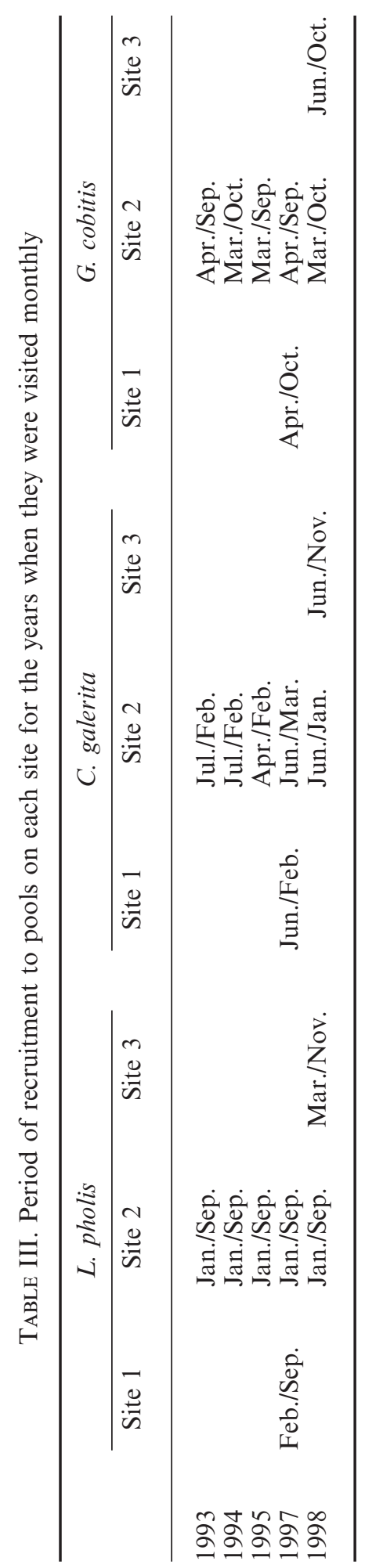


March to July (Faria \& Almada, 1995). The sharp decline of the size classes $>7-8 \mathrm{~cm} L_{\mathrm{T}}$ (Fig. 1) strongly suggests that as the fishes reach this size they begin to leave the pools, a process that extends from October to mid-winter, very probably as successive juveniles reach this critical size. The results of the ANOVA agree with this pattern, and although showing a significant inter-annual effect (Tukey HSD test: 1993/1994, $P<0 \cdot 05 ; 1993 / 1998, P<0 \cdot 01$ ), also revealed a clearly significant monthly effect on the abundance of juveniles (Tukey HSD test: July, August, September, October/the other months $P<0 \cdot 001)$. As the other study sites were monitored monthly only for 1 year each (Table IV), they could not be included in the same analysis, but a correlation between data collected monthly at each site during that year and the corresponding data for site 2 was significant for both sites (site 1/site 2: $r_{\mathrm{s}}=0 \cdot 58, P<0 \cdot 05, n=12$; site $3 /$ site 2 : $r_{\mathrm{s}}=0 \cdot 71, P<0 \cdot 01, n=12$ ), strongly suggesting that the temporal patterns are basically similar across sites. The idea that the fishes leave the pools upon reaching a size threshold of $c .7-8 \mathrm{~cm} L_{\mathrm{T}}$ was also supported by the existence of a statistically significant difference in sizes of fish between channels and pools $\left(\chi^{2}=1134 \cdot 95\right.$, d.f. $\left.=1, P<0 \cdot 001\right)$. While fishes $<7 \mathrm{~cm} L_{\mathrm{T}}$ were significantly more abundant than expected by chance in pools, fishes $>7 \mathrm{~cm} L_{\mathrm{T}}$ were significantly more abundant in channels.

A similar situation occurred with L. pholis (Fig. 1; Tables III and IV) and the results of the ANOVA for site 2 (Table V), that revealed a clearly significant monthly effect on the abundance of juveniles (Tukey HSD test: June, July, August/the other months $P<0 \cdot 001$ ), are likely to be applicable across sites, judging from the highly significant correlations obtained (site $1 /$ site $2: r_{\mathrm{s}}=0 \cdot 88$, $P<0.001, n=12$; site 3/site 2: $r_{\mathrm{s}}=0.75, P<0.01, n=12$ ), with the important difference that the larger fishes began to pass the low tide in crevices instead of moving to the channels as in G. cobitis. Fishes $<7 \mathrm{~cm} L_{\mathrm{T}}$ were significantly more abundant than expected by chance in pools and fishes $>7 \mathrm{~cm} L_{\mathrm{T}}$ in crevices $\left(\chi^{2}=12058 \cdot 2\right.$, d.f. $\left.=1, P<0 \cdot 001\right)$. For this species, fishes recruited to the pools from January to October/November (in Portugal the breeding season extends from October/November to May) (Faria et al., 1996), but left the pools at a size similar to that of G. cobitis and at a similar period, which suggests that their growth in the pools was slower than that of G. cobitis.

In contrast with the other two species, $C$. galerita does not emigrate out of the pools and continues to use them as adults (Fig. 1; Tables III and IV). The only significant difference between months (Table V) is probably explained by the increase of the juveniles by the end of summer due to cumulative recruitment in previous months (Tukey HSD test: June/September $P<0 \cdot 05$ ). The pattern observed in site 2 is consistent with that observed in site 1 (Table IV; $r_{\mathrm{s}}=0 \cdot 70$, $P<0 \cdot 05, n=12$ ), although no significant correlation was found between sites 2 and $3\left(r_{\mathrm{s}}=0.31, P>0.05, n=12\right)$. However, during the breeding season (February/March to September/October; Almada et al., 1996), a substantial number of males leaves the pools temporarily, as indicated by significant differences in the sex-ratio in pools in and out of the breeding season $\left(\chi^{2}=30 \cdot 919\right.$, d.f. $=1, P<0 \cdot 001)$. This reduction in the number of males present in pools is related to the fact that the males seek holes in rocks where they establish nests and guard the eggs, and many of which stay out of water at low tide. Many of the holes that were occupied during the breeding season by males of C. galerita 

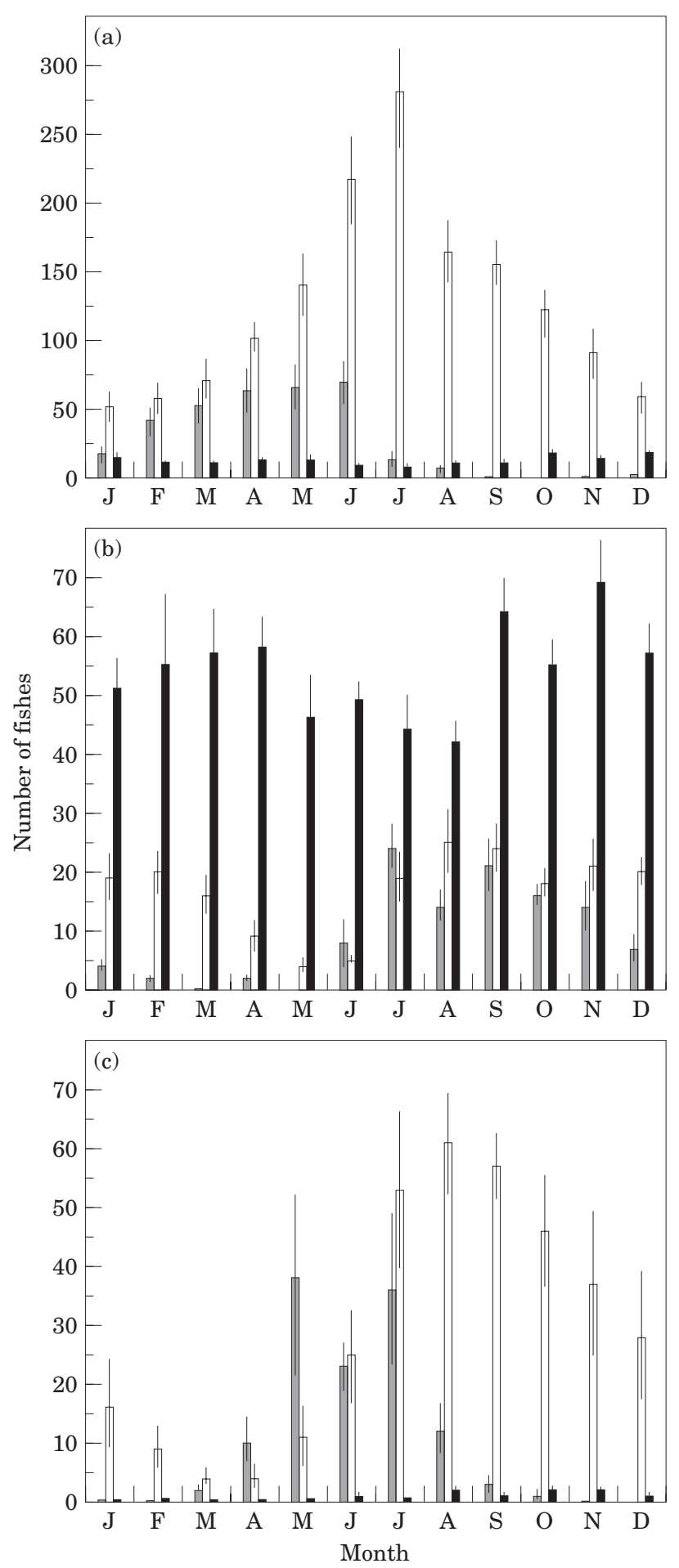

FIG. 1. Recruits (圆), juveniles ( $\square$ ) and adults ( $\square$ ) collected monthly in the 54 pools studied. Monthly values are averaged for the total number of visits at each study site: (a) L. pholis; (b) C. galerita; (c) G. cobitis. 
TABLE IV. Monthly numbers of adult fishes per pool in the three study sites. In the case of site 2 the values are averages of 5 years

\begin{tabular}{|c|c|c|c|c|c|c|c|c|c|}
\hline & \multicolumn{3}{|c|}{ L. pholis } & \multicolumn{3}{|c|}{ C. galerita } & \multicolumn{3}{|c|}{ G. cobitis } \\
\hline & Site 1 & Site 2 & Site 3 & Site 1 & Site 2 & Site 3 & Site 1 & Site 2 & Site 3 \\
\hline Jan. & $0 \cdot 73$ & $0 \cdot 51$ & $0 \cdot 00$ & 0.67 & $1 \cdot 87$ & $0 \cdot 08$ & 0.07 & $0 \cdot 01$ & $0 \cdot 00$ \\
\hline Feb. & $0 \cdot 40$ & $0 \cdot 40$ & $0 \cdot 17$ & $0 \cdot 60$ & $2 \cdot 04$ & 0.58 & $0 \cdot 00$ & $0 \cdot 02$ & $0 \cdot 00$ \\
\hline Mar. & $0 \cdot 33$ & $0 \cdot 36$ & $0 \cdot 17$ & $0 \cdot 47$ & $2 \cdot 12$ & $0 \cdot 50$ & $0 \cdot 13$ & $0 \cdot 02$ & $0 \cdot 00$ \\
\hline Apr. & $0 \cdot 40$ & $0 \cdot 43$ & $0 \cdot 08$ & $0 \cdot 67$ & $2 \cdot 16$ & $0 \cdot 25$ & $0 \cdot 07$ & $0 \cdot 02$ & $0 \cdot 00$ \\
\hline May & $0 \cdot 27$ & $0 \cdot 43$ & $0 \cdot 00$ & $0 \cdot 67$ & $1 \cdot 70$ & $0 \cdot 50$ & $0 \cdot 20$ & $0 \cdot 02$ & $0 \cdot 00$ \\
\hline Jun. & 0.53 & $0 \cdot 30$ & $0 \cdot 00$ & $0 \cdot 73$ & $1 \cdot 81$ & 0.33 & $0 \cdot 00$ & 0.03 & $0 \cdot 00$ \\
\hline Jul. & $0 \cdot 20$ & $0 \cdot 35$ & $0 \cdot 17$ & $0 \cdot 47$ & $1 \cdot 62$ & $0 \cdot 50$ & 0.07 & $0 \cdot 02$ & $0 \cdot 08$ \\
\hline Aug. & $0 \cdot 47$ & $0 \cdot 36$ & $0 \cdot 00$ & $0 \cdot 67$ & $1 \cdot 54$ & $0 \cdot 50$ & $0 \cdot 20$ & $0 \cdot 08$ & $0 \cdot 00$ \\
\hline Sep. & $0 \cdot 07$ & $0 \cdot 37$ & $0 \cdot 50$ & $1 \cdot 07$ & $2 \cdot 37$ & $1 \cdot 17$ & $0 \cdot 13$ & $0 \cdot 04$ & $0 \cdot 00$ \\
\hline Oct. & $0 \cdot 20$ & $0 \cdot 64$ & $0 \cdot 00$ & $1 \cdot 53$ & $2 \cdot 02$ & 0.75 & $0 \cdot 07$ & $0 \cdot 06$ & $0 \cdot 00$ \\
\hline Nov. & $0 \cdot 13$ & $0 \cdot 50$ & $0 \cdot 17$ & $1 \cdot 07$ & $2 \cdot 56$ & 0.83 & $0 \cdot 07$ & $0 \cdot 07$ & $0 \cdot 00$ \\
\hline Dec. & $0 \cdot 53$ & 0.67 & $0 \cdot 08$ & $1 \cdot 07$ & $2 \cdot 10$ & 0.08 & $0 \cdot 00$ & $0 \cdot 04$ & $0 \cdot 00$ \\
\hline
\end{tabular}

TABLE V. Results of a repeated measures ANOVA testing the effect of years and months on the numbers of juveniles on site 2

\begin{tabular}{|c|c|c|c|c|c|c|c|}
\hline \multirow{2}{*}{ Effect } & \multirow{2}{*}{ d.f. } & \multicolumn{2}{|c|}{ L. pholis } & \multicolumn{2}{|c|}{ C. galerita } & \multicolumn{2}{|c|}{ G. cobitis } \\
\hline & & $F$ & $P$ & $F$ & $P$ & $F$ & $P$ \\
\hline Year & 4 & $7 \cdot 00$ & $<0.001$ & $2 \cdot 23$ & ns & $3 \cdot 60$ & $<0 \cdot 01$ \\
\hline Month & 11 & $9 \cdot 78$ & $<0.001$ & $2 \cdot 17$ & $<0.05$ & $8 \cdot 88$ & $<0.001$ \\
\hline Year/month & 44 & $3 \cdot 16$ & $<0.001$ & $2 \cdot 79$ & $<0.001$ & $3 \cdot 49$ & $<0.001$ \\
\hline
\end{tabular}

ns, Non-significant.

and eggs became empty when breeding ceased, corresponding to when the males returned to the pools (Almada et al., 1996).

\section{MICROHABITAT SIMILARITIES AND DIFFERENCES BETWEEN THE SPECIES}

The principal component analysis included the numbers of fishes of each category and the ecological characteristics of the 54 pools studied and was based on a correlation matrix using previously standardized data. A varimax rotation of the resulting matrix was performed (Sokal \& Rohlf, 1973). The three factors extracted explained $67 \%$ of total variance (factor $1,28 \cdot 55 \%$; factor $2,26 \cdot 82 \%$; and factor $3,11 \cdot 60 \%$ ). Inspection of Fig. 2 supports the following conclusions.

(1) There was a high level of association of the first factor with topographic complexity, the abundance of barnacles and sea urchins and the predominance of rocky bottom. Also the juveniles of $L$. pholis and both juveniles and adults of C. galerita were associated strongly with the characteristics that predominate in this axis. 


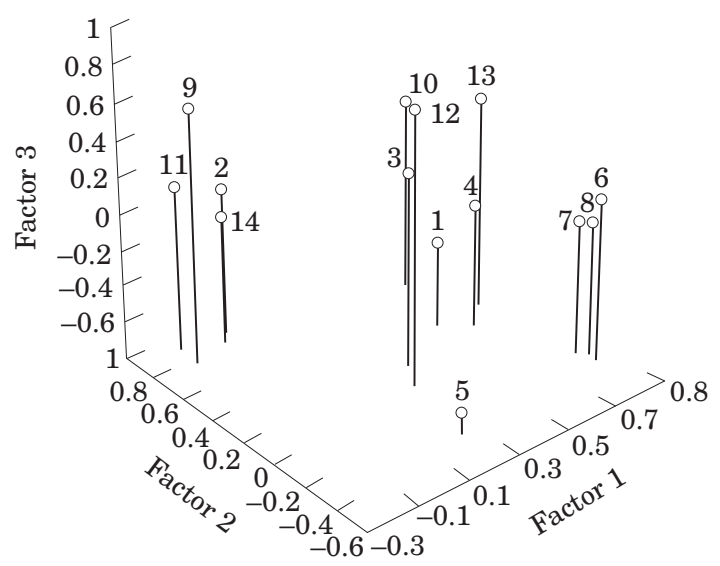

FIG. 2. Result of the principal component analysis that included the numbers of fishes of each size category and the ecological characteristics of the 54 pools studied: 1 , depth; 2, pool surface area; 3, algal cover; 4, complexity; 5 , time of emersion; 6 , type of substratum; 7, sea urchins; 8 , barnacles; 9, recruits of L. pholis; 10, recruits of C. galerita; 11, recruits of G. cobitis; 12, juveniles of L. pholis; 13, juveniles + adults of C. galerita; 14 , juveniles of G. cobitis.

(2) Recruits of $L$. pholis and recruits and juveniles of $G$. cobitis associate strongly with the area of the pools, all of which were elements associated strongly with factor 2.

(3) Finally, in factor 3 a salient feature was the time taken by the tide to reach the pools, which had a strong negative loading in this factor. Both recruits of $L$. pholis and $C$. galerita had strong positive loadings in the factor, which indicate marked preference of these recruits for lower pools, that were isolated from the sea for relatively short periods.

\section{DIFFERENTIAL REMOVAL AND ADDITION EXPERIMENTS}

Several experiments were carried out in which a single species was removed and added to the pools, to test the hypothesis that interspecific interactions would explain the differences in patterns of pool occupation described above. As the gobies were absent from many pools, only the two blennies were involved in the experiments. During the period between 15 and 30 days the composition of the assemblages in pools returned to the pre-treatment levels, both in removal and addition experiments. Neither tests for differences in the number of fishes (Table VI) nor for the proportions of the different species (Table VII) revealed significant differences before and after the experimental treatments.

\section{DISCUSSION}

Overall, the present results confirm those of Gibson (1972) and the emerging picture is one of marked habitat segregation between different species and different life history stages of the same species. Moreover, during its ontogeny each of the three species studied uses a different succession of microhabitats. The adults of $C$. galerita remain in pools, except for a proportion of the breeding males. In contrast, larger L. pholis move from pools to shelters that are emersed 
TABLE VI. Kruskal-Wallis analysis of variance between the number of fishes for each species prior to the manipulation and that found 15 and 30 days after, in 10 control pools, 10 addition pools and 10 removal pools

\begin{tabular}{lllcccc}
\hline \multirow{2}{*}{ Year } & \multirow{2}{*}{ Species } & \multirow{2}{*}{ Period } & \multicolumn{2}{c}{$0-15$ day interval } & \multicolumn{2}{c}{$15-30$ day interval } \\
& & & $H(2, n=30)$ & $P$ & $H(2, n=30)$ & $P$ \\
\hline \multirow{2}{*}{1998} & \multirow{2}{*}{ L. pholis } & May/Jun. & $22 \cdot 192$ & $<0 \cdot 001^{*}$ & 0.948 & $\mathrm{~ns}$ \\
& & Nov./Dec. & 16.901 & $<0 \cdot 001^{*}$ & $2 \cdot 750$ & $\mathrm{~ns}$ \\
1999 & \multirow{2}{*}{ C. galerita } & May/Jun. & $8 \cdot 580$ & $<0 \cdot 01^{*}$ & 1.623 & $\mathrm{~ns}$ \\
& & Nov./Dec. & $18 \cdot 190$ & $<0 \cdot 001^{*}$ & 4.630 & $\mathrm{~ns}$ \\
\hline
\end{tabular}

*All pairs of data showed significant differences (Dunn's test); ns, non-significant.

TABLE VII. Results of the $\chi^{2}$ analysis for the proportion of fishes of the manipulated species over the number of fish of the other species present in pools prior to the manipulation (removal and addition of fish) and that found 15 days after

\begin{tabular}{|c|c|c|c|c|c|c|c|c|}
\hline \multirow{2}{*}{ Year } & \multirow{2}{*}{ Species } & \multirow{2}{*}{ Period } & \multicolumn{2}{|c|}{ Control } & \multicolumn{2}{|c|}{ Removal } & \multicolumn{2}{|c|}{ Addition } \\
\hline & & & $\chi^{2}$ & $P$ & $\chi^{2}$ & $P$ & $\chi^{2}$ & $P$ \\
\hline \multirow[t]{2}{*}{1998} & L. pholis & May/Jun. & $0 \cdot 099$ & ns & $1 \cdot 410$ & ns & $0 \cdot 448$ & ns \\
\hline & & Nov./Dec. & $2 \cdot 622$ & ns & 0.532 & ns & $1 \cdot 034$ & ns \\
\hline \multirow[t]{2}{*}{1999} & C. galerita & May/Jun. & $1 \cdot 252$ & ns & $0 \cdot 000$ & ns & $3 \cdot 546$ & ns \\
\hline & & Nov./Dec. & $0 \cdot 230$ & ns & $1 \cdot 140$ & ns & $2 \cdot 430$ & ns \\
\hline
\end{tabular}

periodically during low tides, while G. cobitis that settled in pools as juveniles move subsequently to channels as they grow larger.

Microhabitat segregation with regard to breeding sites is also quite marked. Although L. pholis and C. galerita both nest in holes and crevices, the size of the cavities differs clearly between those two species whose adult body sizes are very different (Zander, 1986). In a previous study of the nest sites of G. cobitis and another species, G. paganellus that occurs in the same habitat, Faria \& Almada (1995) found a similar situation, with the larger species, G. cobitis, using the larger boulders.

In summary, all the resident rocky intertidal fish species considered in this study are quite specific in the microhabitats they use both for shelter and breeding sites. These patterns of microhabitat separation would traditionally be taken as strong evidence that interspecific competition, present or past (Jackson, 1981) has been a major structuring force in this fish assemblage, as suggested by many authors for other species assemblages (Schoener, 1974; Itzkowitz, 1977; Wiederholm, 1987). This hypothesis may seem further supported by the findings of many studies that found evidence in favour of strongly deterministic controls and regulation of rocky intertidal fish communities (Thomson \& Lehner, 1976; Grossman, 1982, 1986; Faria \& Almada, 1999). 
However, it is argued that interspecific competition, at least in the present study, is unlikely to explain the patterns of microhabitat segregation. The conclusion is based on three arguments.

(1) The addition and removal experiments did not provide any evidence of one of the species being able to control the numbers of the other and rather point to the operation of intraspecific mechanisms, that would set limits to the numbers of individuals of a given species that each pool is able to maintain. Possibly, each pool offers a limited number of shelters suitable for each species and size class and the excess of fishes that are not able to secure those shelters are forced to leave. This view is supported by the finding of high levels of correlation in the numbers of fishes of each species present in the same set of pools between different years (Faria \& Almada, 1999).

(2) At least presently, the microhabitats of blennies and gobies, are so different that the likelihood of direct interactions between these elements of the assemblage is very low.

(3) While the pools allow coexistence of juveniles of more than one species, only the adults of $C$. galerita remain in the same type of pools. The juveniles of L. pholis and G. cobitis grow much faster than those of C. galerita (Faria et al., 1996) and begin to leave the pools when they are larger than C. galerita, so it is very unlikely that they are forced to leave aggressively by the last species.

Competition in the past could explain the present results but alternative hypotheses are possible. Juveniles of L. pholis and C. galerita of comparable size interact agonistically in experimental conditions (Faria \& Almada, 1998), with $C$. galerita being dominant over $L$. pholis. The food of small juveniles of $L$. pholis and C. galerita of similar size overlaps considerably (Qasim, 1957; Gibson, 1972; Milton, 1983). However, as L. pholis grows, the species diverge so much in size that not surprisingly the much larger $L$. pholis tolerates longer times of emersion, needs larger crevices as shelter and begins to eat different and larger food items (Qasim, 1957; Gibson, 1972). In broad terms, it may be said that $L$. pholis grows faster than C. galerita even after the onset of reproduction (Faria et al., 1996) and eventually has different niche requirements. The life history of L. pholis is thus characterized by a succession of niche shifts that are much less marked in C. galerita and the ecological requirements of both species become increasingly divergent.

In both blenniids and gobiids, there are co-occurring species pairs (L. pholis vs C. galerita; G. cobitis vs G. paganellus) with very large differences in adult sizes, with the largest species being two or three times larger than the smallest (see figures for adult size in Zander, 1986). These differences could have evolved through past interspecific competition. Also, they could have arisen by other mechanisms; namely, slight differences in anatomy and behaviour of the ancestors of the larger species could have allowed more efficient acquisition of larger prey, thus leading to benefits from faster growth and expansion into niches not usable by the smaller member of the pair, even without competition. Thus the role of past competition is far from obvious in this case, although it remains an open issue.

Part of this study was supported by Fundação para a Ciência e Tecnologia (FCT) as part of the projects PRAXIS XXI/3/3.2/EMG/1957/95 and the Pluriannual Program 
(UI\&D 331/94). C.F. was also supported by a grant from FCT (PRAXIS XXI/BD/5666/ 95). We thank T. Avelar who revised the English; A. Martins, C. Silva, C. Nunes, C. Luis, M. Silva, J. A. Oliveira, T. Leitao and V. Carvalho for help in the field work; R. N. Gibson for his invaluable editorial comments and criticisms; and two anonymous referees for suggestions.

\section{References}

Alevizon, W., Richardson, R., Pitts, P. \& Serviss, G. (1985). Coral zonation and patterns of community structure in Bahamian reef fishes. Bulletin of Marine Science 36, 304-318.

Almada, V. C., Carreiro, H., Faria, C. \& Gonçalves, E. J. (1996). The breeding season of Coryphoblennius galerita in Portuguese waters. Journal of Fish Biology 48, 295-297.

Burgess, T. J. (1978). The comparative ecology of two sympatric polychromatic populations of Xererpes fucorum Jordan \& Gilbert (Pisces: Pholididae) from the rocky intertidal zone of Central California. Journal of Experimental Marine Biology and Ecology 35, 43-58.

Clarke, R. (1989). Population fluctuation, competition and microhabitat distribution of two species of tube blennies, Acanthemblemaria (Teleostei: Chaenopsidae). Bulletin of Marine Science 44, 1174-1185.

Connel, S. D. \& Jones, G. P. (1991). The influence of habitat complexity on postrecruitment processes in a temperate reef fish population. Journal of Experimental Marine Biology and Ecology 151, 271-294.

Costello, M. J. (1992). Abundance and spatial overlap of gobies (Gobiidae) in Lough Hyne, Ireland. Environmental Biology of Fishes 33, 239-248.

Estabrook, C. B. \& Estabrook, G. F. (1989). ACTUS: a solution to the problem of small samples in the analysis of two-way contingency tables. Historical Methods 22, $5-8$.

Faria, C. \& Almada, V. C. (1995). Some aspects of the breeding ecology of Gobius cobitis Pallas and Gobius paganellus L. in the west coast of Portugal. Arquivos do Museu Bocage, Nova Série II, 463-471.

Faria, C. \& Almada, V. (1998). Patterns of agonistic behaviour, shelter occupation and habitat preference in juvenile Lipophrys pholis, Coryphoblennius galerita and Gobius cobitis. Journal of Fish Biology 53, 1263-1273.

Faria, C. \& Almada, V. (1999). Variation and resilience of rocky intertidal fish in western Portugal. Marine Ecology Progress Series 184, 197-203.

Faria, C., Almada, V. C. \& Gonçalves, E. J. (1996). Juvenile recruitment, growth and maturation of Lipophrys pholis (Pisces: Blenniidae), from the west coast of Portugal. Journal of Fish Biology 49, 727-730.

Gibson, R. N. (1967). Studies on the movements of littoral fish. Journal of Animal Ecology 36, 215-234.

Gibson, R. N. (1969). The biology and behaviour of littoral fish. Oceanography and Marine Biology: An Annual Review 7, 367-410.

Gibson, R. N. (1972). The vertical distribution and feeding relationship of intertidal fish on the Atlantic coast of France. Journal of Animal Ecology 48, 189-207.

Gibson, R. N. \& Yoshiyama, R. M. (1999). Intertidal fish communities. In Intertidal Fishes: Life in Two Worlds (Horn, M. H., Martin, K. L. \& Chotkowski, M. A., eds), pp. 264-296. San Diego: Academic Press.

Greenfield, D. W. \& Johnson, R. K. (1990). Community structure of western Caribbean blennioid fishes. Copeia 1990, 433-448.

Grossman, G. D. (1982). Dynamics and organization of a rocky intertidal fish assemblage: the persistence and resilience of taxocene structure. The American Naturalist 119, 611-637.

Grossman, G. D. (1986). Long term persistence in a rocky intertidal fish assemblage. Environmental Biology of Fishes 15, 315-317. 
Itzkowitz, M. (1977). Spatial organisation of the Jamaican damselfish. Journal of Experimental Marine Biology and Ecology 28, 217-241.

Jackson, B. C. (1981). Interspecific competition and species distributions: the ghosts of theories and data past. American Zoologist 21, 889-901.

Koppel, V. H. (1988). Habitat selection and space partitioning among two Mediterranean blenniid species. P.S.Z.N. I. Marine Ecology 9, 329-346.

Kotrschal, K. (1988). Blennies and endolithic bivalves: differential utilization of shelter in Adriatic Blenniidae (Pisces: Teleostei). P.S.Z.N. I. Marine Ecology 9, 253-269.

Larson, R. J. (1980a). Competition, habitat selection and the bathymetric segregation of two rockfish (Sebastes) species. Ecological Monographs 50, 221-239.

Larson, R. J. (1980b). Territorial behaviour of the black and yellow rockfish and gopher rockfish (Scorpaenidae, Sebastes). Marine Biology 58, 111-122.

Larson, R. J. (1980c). Influence of territoriality on adult density in two rockfishes of the genus Sebastes. Marine Biology 58, 123-132.

Luckhurst, B. E. \& Luckhurst, K. (1978). Analysis of the influence of substrate variables on coral reef fish communities. Marine Biology 49, 317-323.

MacPherson, E. (1981). Resource partitioning in a Mediterranean demersal fish community. Marine Ecology Progress Series 4, 183-193.

MacPherson, E. (1994). Substrate utilisation in a Mediterranean littoral fish community. Marine Ecology Progress Series 114, 211-218.

Mayr, M. \& Berger, A. (1992). Territoriality and microhabitat selection in two intertidal New Zealand fish. Journal of Fish Biology 40, 243-256.

Milton, P. (1983). Biology of littoral blenniid fishes on the coast of south-west England. Journal of the Marine Biological Association of the United Kingdom 63, 223-237.

Pitts, P. A. (1991). Comparative use of food and space by three Bahamian butterflyfishes. Bulletin of Marine Science 48, 749-756.

Qasim, S. Z. (1957). The biology of Blennius pholis L. (Teleostei). Proceedings of the Zoological Society of London 128, 161-208.

Raffaelli, D. \& Hawkins, S. (1996). Intertidal Ecology. London: Chapman \& Hall.

Robertson, D. R. \& Lassig, B. (1980). Spatial distribution patterns and coexistence of a group of territorial damselfishes from the Great Barrier Reef. Bulletin of Marine Science 30, 187-203.

Schoener, T. W. (1974). Resource partitioning in ecological communities. Science 185, 27-39.

Sokal, R. R. \& Rohlf, F. J. (1973). Introduction to Biostatistics. San Francisco: W. H. Freeman.

Smith, C. L. \& Tyler, J. C. (1973). Direct observations of resource sharing in coral reef fish. Helgoländer Meeresuntersuchungen 24, 264-275.

Syms, C. (1995). Multi-scale analysis of habitat association in a guild of blennioid fishes. Marine Ecology Progress Series 125, 31-43.

Thomson, D. A. \& Lehner, C. E. (1976). Resilience of a rocky intertidal fish community in a physically unstable environment. Journal of Experimental Marine Biology and Ecology 22, 1-29.

Wiederholm, A-M. (1987). Habitat selection and interactions between three marine fish species (Gobiidae). Oikos 48, 28-32.

Wilkins, H. K. A. \& Myers, A. A. (1993). Shelter utilization by Gobius cruentatus and Thorogobius ephippiatus (Teleostei: Gobiidae). Journal of Fish Biology 43, 763-773.

Yoshiyama, R. M. (1980). Food habits of three species of rocky intertidal sculpins (Cottidae) in Central California. Copeia 1980, 515-525.

Yoshiyama, R. M. (1981). Distribution and abundance patterns of rocky intertidal fishes in central California. Environmental Biology of Fishes 6, 315-332.

Yoshiyama, R. M., Sassaman, C. \& Lea, R. N. (1986). Rocky intertidal fish communities of California: temporal and spatial variation. Environmental Biology of Fishes 17, $23-40$. 
Zander, C. D. (1982). Feeding ecology of littoral gobiid and blennioid fish of the Banyuls area (Mediterranean Sea). I. Main food and trophic dimension of niche and ecotope. Vie Milieu 32, 1-10.

Zander, C. D. (1986). Blenniidae. In Fishes of the North-Eastern Atlantic and the Mediterranean (Whitehead, P. J. P., Bauchot, M.-L., Hureau, J.-C., Nielsen, J. \& Tortonese, E., eds), pp. 1096-1112. Paris: UNESCO. 